\title{
Capacity Building for School Improvement: A Case Study of a New Zealand Primary School
}

\author{
Paper presented to the Asia-Pacific Educational Research Conference, National \\ institute of Education, Singapore
}

November 28, 2008

\section{PATRICIA STRINGER}

\begin{abstract}
Capacity building is now mentioned synonymously with school improvement in much of the literature with an absence of debate on the implications of political, social and economic trends. The paper explores capacity building in one low decile, multicultural, New Zealand primary school. The research, positioned within an interpretivist paradigm, utilises a case study and grounded theory approach to explore four aspects: 1. processes that enhance improvement; 2. internal and external influences on capacity building; 3. wider societal factors that influence the development of capacity; and 4. links between capacity building and improvement.
\end{abstract}

The paper suggests that capacity building for school improvement is time and context dependent and is unique to the setting. It occurs in response to individual, collective and systemic need in ways that sustain equilibrium while moving towards improvement. The paper explores key attributes of capacity building: vision; stakeholders as change agents; school culture; and professional development. Practices that are examined include knowledge production and utilisation; division of labour: roles and responsibilities; and a switching-on mentality. These groups of factors lend themselves to a discussion of four important themes in the capacity building and school improvement process: situated activity; connectedness; leadership, governance and management; and outcomes. The paper concludes that the confluence of these contributing factors enables tensions and needs of context to be managed in ways that ensure equilibrium of people, school and system while moving in the direction of improvement.

\section{Introduction:}

In New Zealand, much emphasis has and continues to be directed towards school improvement in pursuit of raising student achievement and reducing disparity (Ministry of Education, 1999, 2004; Alton-Lee, 2003). The government's agenda is on enhancing New Zealand's social and economic well being, adaptability to technological advancements, addressing issues of diversity and developing a push for lifelong learning. Despite a mass of legislation, policies and research aimed at reform, contemporary literature suggests school improvement is accompanied by tensions, such as:

- Funding shortages that limit strategic capabilities of schools to have an impact on capacity building for improvement (Dalin, 2005; Hawk \& Hill, 1997).

- Accountability demands that can be potentially challenging to administer in practice. For example, recent legislative changes to governance aspects of schooling have increased school boards' responsibilities in monitoring student achievement and reviewing effectiveness of teaching and learning in relation to set expectations. However, as Timperley, Smith, Parr, Portway, Mirams, Clark, Allen and Page (2004) claim, in Analysis and Use of Student Achievement Data, boards do not have direct involvement with students and programmes at the classroom level; these responsibilities are inevitably exercised through accountability links with professionals and are, at best, tenuous for parent board members. Timperley et al.'s 
(2004) claim that lack of knowledge of governance and limited participation in educational matters mean some boards of trustees are unlikely to exercise their accountability roles effectively. Questions raised subsequently concern the effectiveness, nature and type of board contribution that enhances capacity building for improvement.

- Socio-economic issues facing schools in low decile areas result in a range of challenges, problems and opportunities. The Ministry of Education, educators / researchers (Hawk \& Hill, 1997; McCauley \& Roddick, 2001) and Education Review officials (ERO, 2000) suggest that socio-economic issues limit school improvement.

- Ongoing reform agendas and the push for continuous change leave some schools struggling to cope. Elmore (1995) cautions that schools, in their quest to keep up with change demands, end up altering structures and 'adding-on' programmes which strain their ability to operate strategically.

Tensions of context have implications for stakeholders faced with building capacity for improvement. This research project was framed by four aims: 1 . to undertake an investigation on processes that enhance improvement, namely, capacity building for school improvement; 2. to define capacity building; 3. to conduct an in-depth study of influences (external and internal) on capacity building for school improvement; and 4. to record the journey one multicultural ${ }^{1}$, low decile ${ }^{2}$, state primary school undertook in the building of capacity for improvement. In this paper, the following are examined: 1 . processes that enhance improvement; 2. internal and external influences on capacity building; 3. wider societal factors that influence the development of capacity; and 4. links between capacity building and school improvement.

\section{The Research Project}

In what follows, an outline of the research design is summarised before the results and major implications discussed. The research, positioned within an interpretivist paradigm, employs a case study approach and grounded theory methods for data analysis.

\section{Interpretivist paradigm}

There are two essential elements which dictated an interpretivist approach. First, it was important to investigate capacity building for school improvement through the eyes of participants; that is, to examine the phenomena, "as consisting of the intrinsic meanings shared by members of a social group which are sustained by the actions and interactions of the members" (Clark, 1997, p. 37). Ontological ${ }^{3}$ questions pertained to perceptions of how stakeholder activity, professional development, school culture and vision contributed to capacity building for school improvement; how external factors influenced the building of

\footnotetext{
${ }^{1}$ Assuming that the dominant culture in most New Zealand schools is usually European/Pakeha, a multicultural school is defined by ERO (2000) as "A school in which students from at least two other ethnic groups comprise at least 20 percent of the school's population. The 20 percent threshold is low enough to capture all schools with a significant population of students of other cultures, yet not so low that the definition loses its value and meaning” (p. 3).

${ }^{2}$ Every state school in New Zealand is allocated a decile (10 percent grouping) by which to target funding based on the degree of socio-economic disadvantage the community from which the students are drawn. "Low decile schools (1-3) draw from communities with the highest degree of disadvantage while high decile schools (8-10) draw from communities with the lowest degree of socio-economic disadvantage. A school's decile ranking is calculated using six dimensions: equivalent household income; parental occupation; household crowding; parent's educational qualifications; income support payments received by parents; and the portion of students of Maori or Pacific ethnicity” (Ministry of Education, 1999, p. 8).

${ }^{3}$ The ontological question: "What is the form and nature of reality and, therefore, what is there that can be known about it?” (Guba \& Lincoln, 1994, cited in Denzin \& Lincoln, 1994, p. 108).
} 
capacity; and perceived links between capacity and school improvement. Epistemologically ${ }^{4}$, the need for personal renditions, albeit subject to change and reconfiguration, required joint (researcher / participants) construction of meaning to achieve understanding of processes, motives, desires, beliefs, values and attitudes of individuals and groups in the capacity building process. Subjective meaning, understood within a social context of shared concepts and common language, meant there was no one 'correct' way of perceiving reality, nor was there an absolute truth. The research design required a methodology ${ }^{5}$ that was participative and collaborative - an interpretivist approach.

The second justification for using the interpretivist paradigm reasoned human actions affect perceived reality. As Clark (1997) argues, "meaning is internal to action, it is what makes an act an act rather than just being behaviour; it gives it intelligibility" (p. 38). This research required an interpretivist paradigm as it concerned perceptions of people; human action as an essential component of capacity building for school improvement.

\section{Case Study Approach}

The research adopted a case study design that was both instrumental (Stake, 2003) and explanatory (Yin, 1994; 2003). It sought deeper insights into the concept of capacity building for school improvement in one school site and answers to "how" and "why" process related operational questions. The study focused on explanations of the, "phenomenon within its reallife context”; a situated, localised boundary of space and time (Yin, 2003, p. 13).

\section{Selection of the Case}

The inquiry is a qualitative study. It focused on achieving depth of understanding of the concept, capacity building, in a single case purposefully selected. Patton (1990) explains, "The logic and power of purposeful sampling lies in selecting information-rich cases for study in depth. Information rich cases are those from which one can learn a great deal about issues of central importance to the purpose of the research, thus the term purposeful sampling” (p. 169 italics in the original).

In this research, intensity sampling, snowball or chain sampling, criterion sampling and opportunistic sampling were utilised in site selection. For example, talks with groups such as Resource Teachers for Learning and Behaviour (RTLBs) and TEAM Solutions ${ }^{6}$ and observations at school events identified this school as information-rich because of its practices: a strong drive for organisational change based on the school's vision; professional leadership; an emphasis on student achievement, teaching and learning; a supportive school culture; and well supported, continuous professional development associated with staff and student learning.

\section{A Brief Description of the School}

This is a state primary school located in Auckland, New Zealand. It is a contributing (Year 16 ) school with a decile two ranking. At the time of data collection in 2004, the roll was approximately 330 with just over 20 teachers.

It is a multicultural school that serves a diverse community. Its ethnic composition includes: New Zealand European/Pakeha, 16\%; Samoan, 14\%; Tongan, 11\%; Indian, 11\%; Maori, 10\%; Ethiopian, 6\%; Somalian, 5\%; Niuean, 4\%; Cook Island, 4\% and "other", 19\% (ERO report, 2005). The low socio-economic background of many students combined with the

\footnotetext{
${ }^{4}$ The epistemological question: "What is the nature of the relationship between the knower or wouldbe-knower and what can be known?” (ibid.).

${ }^{5}$ The methodological question: "How can the inquirer (would-be-knower) go about finding out what ever he or she believes can be known?” (ibid.).

${ }^{6}$ TEAM Solutions is an external agency that offers assistance to schools. TEAM Solutions is government subsidised.
} 
influx of refugee migrant families presents this school with many challenges in, for example, curriculum delivery and meeting the needs of a diverse student / community population.

The school has been acknowledged by the educational community as having achieved a remarkable turnaround over a short time span of two years. The latest ERO (2005) report claims students express pride in their school, meet high expectations set for them, benefit from a wide range of learning and cultural experiences, engage in positive student-staff relationships and take advantage of opportunities to participate in school-wide decision making. Of interest are ERO's comments on professional learning, leadership, and school and community partnerships. The school is acknowledged as having a professional learning culture aimed at improving teaching and learning. A strong focus on developing community is evident in efforts to promote parental involvement in school life.

\section{Fieldwork and Data Collection}

The fieldwork phase of data collection extended over a period of twelve months and generally included staff and team meeting days. Journal entries and photographs recorded participants' stories and experiences. Journal entries provided descriptive accounts of specific actions and corresponding conditions. They also facilitated the recording of feelings, reflections and reactions to experiences encountered. They enhanced interpretation of data commensurate with early analysis and gradual emergence of theory.

An interpretive case study and use of grounded theory methods meant field work could not be confirmed in advance. While observations, interview schedules and document analysis were initially devised in accordance with inquiry aims, the actual design unfolded as data collection proceeded. Design flexibility related to the open-ended nature of this inquiry and a pursuit of understanding complexity. Follow up requests by the principal, deputy principal and other staff members to attend and record what happens at other than intended meetings proved opportunistic as supplementary information, useful in confirming and saturating emerging categories and themes, became available. Patton (1990) endorses this as doing what makes sense and reporting, "fully on what was done, why it was done, and what the implications are for findings” (p. 62).

Although key tools for data collection were interviews, observations and document analysis, all activity pertaining to how this school built its capacity for school improvement was considered data. The focus consistently remained on:

- Stakeholder activity in the capacity building process; their visible and invisible roles and responsibilities;

- Processes, systems and structures that built capacity; an examination of practice;

- Frequency, type and nature of outside agency input in capacity building;

- Parent involvement particular to site and in line with inquiry aims;

- Professional development and processes for knowledge production and utilisation. This included knowledge management with the potential to change practice;

- Descriptions, purpose, quality and nature of site interaction linked to capacity building;

- Cultural artefacts;

- Group norms; and

- Philosophical underpinnings used to define 'work' in this school.

\section{Interviews}

Interviews conducted included individual in-depth interviews, informal interviews by way of conversations and group interviews. Individual interviews utilised guidelines to initiate thought and appropriate an overall sense of direction. School participants interviewed were: three senior managers (principal, deputy principal and assistant principal); three senior teachers with syndicate responsibilities; eight classroom teachers; two specialist teachers; four 
teacher aides; and two support staff. Selection of classroom and specialist teachers resulted from employing purposive sampling techniques. Participants invited to participate had been involved in initiating school improvement over a three year period, had experienced school change and represented different levels of school organisation (junior, middle and senior) with various roles and responsibilities. Four parents, two board members and four representatives from outside agencies (Ministry of Education and service providers) were also interviewed. Participant selection here was also purposefully determined. All had experienced this school's change in various ways over a three year period. Additionally, they had contributed to and, to some degree, continued to maintain involvement in the school's ongoing improvement drive.

Unscheduled, informal interviews assumed the form of informal conversations or chats, valued for their ability to clarify points and connect with incidents that occurred during the day. Informal conversations with participants more intimately involved in the research (senior managers and participants who had signed the interview section of the consent form) provided valuable feedback on unfolding situational events (Patton, 1990). This increased the salience and relevance of events observed. In this inquiry, the spontaneity and flexibility with which these interviews occurred provided a means to follow up leads. As Glaser and Strauss (1967) and Strauss (1987) note, this technique is integral to theoretical sampling. Informal conversations combined with observations engendered greater appreciation of capacity building events in context.

Two group interviews were held with small groups of school personnel: the senior management team (interviewed in the early phase of data collection) and bilingual support workers and associated teacher representatives (interviewed towards the end of data collection). Participants in each formed a relatively homogenous group. Senior managers were asked to consider the journey the school had taken towards improvement over a three year period. Participants were able to respond to each others' comments and the ensuing dialogue produced high quality data with respect to structures and procedures that led to school improvement, outside facilitators' involvement in the process, change in terms of school culture, staff development, leadership and the emotional impact of the 'journey'. Participants in the bilingual support group were asked to reflect on how their input facilitated the building of school capacity in terms of home-school partnerships. Data collected related to how changes in community demographics had impacted on the school and ways in which the school managed such change. Issues discussed related to meeting the diverse needs of 'refugee' parents and students from countries such as Ethiopia and Somalia, restructuring school systems to accommodate cultural differences and tapping into wider community networks to support programmatic change.

Group interviews provided a form of quality control as participants tended, "to provide checks and balances on each other" (Patton, 1990, p. 336). Topics of interest, important to participants, surfaced and it was fairly easy to assess consistency of response in terms of shared views expressed. Advantages of group interviews far outweighed any disadvantages associated with time constraints, note taking difficulties, and conflicting points of view (Patton, 1990).

\section{Observations}

Observation, defined as the watching of behavioural patterns of people in certain situations to obtain information about the phenomenon of interest (Johnson \& Christensen, 2004), facilitated recordings of actual behaviour rather than reports of intended behaviour. In this inquiry, observations heightened sensitivity towards patterns of behaviour that made sense in the social setting. Furthermore, negotiation of situational identity, validation of behaviour as a result of internal and external influences and establishment of contextualised meaning symbolic of participant reality were observable. Observations, conducted in a purposive and appropriate way, provided a window by which to view, "the phenomenological complexity of 
the world where connections, correlations and causes can be witnessed as and how they unfold” (Adler \& Adler, 1994 in Denzin \& Lincoln, 1994, p. 378).

Participant and non-participant observations were employed but on different occasions and for different purposes. Participant observation, a technique which involves entering and being involved with the area being studied, were conducted at home-school events such as the Fun Fiesta night. Such events provided opportunities to observe and contribute to collective activity that generates capacity.

Non-participant observation at the school level entailed, "the systematic noting and recording of events, behaviour, and artefacts (objects) in the social setting chosen for study" (Marshall and Rossman, 1995, p. 79). Written consent from all participants meant observations could be conducted at negotiated meetings such as school, team and literacy professional development meetings. At such venues, interconnections among individuals and groups, teacher talk, negotiation and decision making processes and systemic and structural change that advanced capacity were witnessed. Data that explained the acquisition and dissemination of individual, collective and systemic knowledge to reach all levels of the school was also evidenced. Observational data was used to corroborate information gleaned from other sources and saturate emerging categories and sub-categories. Non-participant observations at board of trustees, 'Friends of the School', cultural groups, home-school partnership meetings and 'parent chat' gatherings provided opportunities to witness community contribution to the capacity building process.

\section{Document Analysis}

Schools are knowledge-based organisations operating in the field of knowledge management. Knowledge, progressively accumulated, acquired, recorded and stored in the form of documents, is a ready source of information. In this study, negotiated access to selected documents provided a way to corroborate evidence. Systematic analysis of documents such as curriculum reviews, strategic plans, charters, ERO reviews, policy manuals and school newsletters provided:

- An impression of patterns and key features of capacity building for school improvement;

- Evidence of conditional pathways of influence of critical events / incidents and practices across the organisation; and

- Corroborated evidence regarding the phenomenon in question.

Data gathered from interviews, observations and document analysis helped construct a worthwhile story; a substantive theory of capacity building for improvement. Research rigour was further ensured by meticulous use of grounded theory methods in data analysis and interpretation.

\section{Grounded Theory Methods for Data Analysis - A Personal Choice}

Grounded theory is, "a general methodology for developing theory that is grounded in data systematically gathered and analysed" (Strauss \& Corbin, 1994, p. 273).The intention is to generate theory reflective of the interplay between analysis and data collection and further analysis, the constant comparative method ${ }^{7}$ (Glaser, 1992).

Use of grounded theory methods suited this inquiry as capacity building for school improvement is an area which has had little or no prior investigation and where applicable conceptual frameworks are unavailable within which to investigate the phenomenon (Strauss

\footnotetext{
${ }^{7}$ Constant comparison method: "generate concepts: categories and their properties to extend and saturate the theory” (Glaser, 2001, p. 40).
} 
\& Corbin, 1998). Glaser and Strauss' (1967) stance on theory building, that is, 'construction' of theory through discovery, was considered particularly apt.

Glaser and Strauss promote two types of theory using a grounded approach. The first is substantive theory that emerges, "from the study of a phenomenon situated in one particular situation context" (Strauss \& Corbin, 1990, p. 174). The second type of theory is formal theory ${ }^{8}$ developed, "for a formal, or conceptual, area of sociological inquiry" (Glaser \& Strauss, 1967, p. 32). Such theories are less specific to a group or place and are usually derived from studying the phenomena under a variety of conditions. In this inquiry, use of grounded theory methods produced a substantive theory on the phenomenon with potential for extension to more formal application in 'other' sites.

Grounded theory methods, noted for their rigour, provided a systematic way of constructing a substantive theory. Here, microanalysis or line by line examination of data proved advantageous. Microanalysis ${ }^{9}$, the technique used in developing open ${ }^{10}$ and axial ${ }^{11}$ codes (Strauss \& Corbin, 1998), involved systematic, line-by-line examination of data. Microscopic examination of interview data, for example, focused on participants' perceptions of capacity building for school improvement. Microanalysis of observational data focused on data chunks, labelled episodes, in much the same way and for similar reasons. In terms of observational data, written recordings of events, happenings and actions were used to conduct the analysis. Microanalysis encouraged close listening to participants' voices to understand how certain events were interpreted. It allowed in vivo codes ${ }^{12}$ to surface and guide the naming of categories. Microscopic analysis generated 'Who?', 'What?', 'Where?', 'When?', 'Why?' and 'How?' questions of properties, dimensions and conditions, giving emerging categories and sub-categories greater explanatory power (Strauss \& Corbin, 1998).

Although the initial open coding phase produced copious quantities of codes, continual verification and subsequent modification, saturation and placement of each code in relationship to other codes had the desired effect of slowing the process down. Coded elements were then organised into categories together with their sub-categories. In the open coding process, memo writing proved useful as a way of guiding, tracking and, as Strauss (1987) notes, "(moving) the analyst further from the data into a more analytic realm” (p.32). Initially, memos were used to make sense of initial interpretations. They highlighted ideas, hunches and new insights. As the coding process became more intense and delved deeper into concepts and categories, memo writing supported theorising to reveal capacity building attributes of vision, school culture, stakeholders as change agents and professional development.

\footnotetext{
${ }^{8}$ Formal Theory: "More formal theories are less specific to a group and place, and as such, apply to a wider range of disciplinary concerns and problems. Formal theories usually are derived from studying phenomena under a variety of conditions such as researching disclosure/nondisclosure under conditions of people acting as spies, engaged in illicit relationships, carrying out illegal activities such as theft, belonging to secret societies and groups, or picking up on someone in a bar or on a street corner" (Strauss \& Corbin, 1998, p. 23).

${ }^{9}$ Microanalysis: "The detailed line-by-line analysis necessary at the beginning of a study to generate initial categories (with their properties and dimensions) and to suggest relationships among categories; a combination of open and axial coding” (Strauss and Corbin, 1998, p. 57).

${ }^{10}$ Open coding: "The analytic process through which concepts are identified and their properties and dimensions are discovered in data” (Strauss \& Corbin, 1998, p. 101).

${ }^{11}$ Axial coding: "The process of relating categories to their subcategories, termed "axial” because coding occurs around the axis of a category, linking categories at the level of properties and dimensions" (Strauss \& Corbin, 1998, p. 123).

${ }^{12}$ In vivo codes are taken from or derived directly from the language of the substantive field. In vivo codes "tend to be the behaviours or processes which will explain to the analyst how the basic problem of the actors is resolved or processed. These codes fracture the data directly because they represent analytic categories as used by the researcher" (Strauss, 1987, p33).
} 
In this inquiry, category names were derived from the literature (professional reading), taken directly from the substantive field by way of "in vivo" codes and sourced from the researcher's professional and theoretical knowledge and experience.

Following open coding of the data, rearrangement into axial codes added more conceptual depth to the analysis. Questions such as: 'Who?', 'What?', 'Where?', 'When?', 'Why?', 'How?' and 'With what consequences?' invoked responses that further illuminated relationships among the attributes. The axial coding process facilitated the development of a combined interview-observation data schedule that represented categories and sub-categories across all data sets.

Open and axial coding occurred before selective coding. In the selective coding process, the core category central to the topic of inquiry became the focus. The core category, in this inquiry, was school vision. Distinguishing characteristics of the core category were seen as:

- Being central and mentioned frequently;

- Being naturally connected to other categories with recorded linkages in memos during the selective coding process;

- Not leading to dead ends;

- Having properties that vary; and

- Representing the participant's main concern (Glaser, 1978).

Two frameworks provided by Strauss and Corbin (1990) for examining relationships and process are the paradigm model and the conditional matrix. Both are intended to make emerging theory denser, more complex and more precise (Charmaz, 2003). In this inquiry, the paradigm model was used. It helped sharpen explanations of processes, relationships and the influence of context on capacity building for school improvement.

\section{Data Analysis}

As indicated, grounded theory methods were used to conduct the data analysis. The researcher remained open-minded and flexible to the significance of the data and interpretations throughout the research process. Such an analysis is akin to a process of discovery rather than the proving of a pre-determined hypothesis. A focus on meaning making through discovery aligns well with this inquiry's location within the interpretivist paradigm.

The researcher began with the initial analysis of interview transcripts followed by analysis of observational and documentation data. Every unit of data was coded and grouped into tentative categories and subcategories using the following process. For example, the first transcript was read to ascertain data that appeared significant to capacity building. A second reading of the same transcript prompted the underlining of key phrases, words or sentences that had deliberate bearing on the phenomena. Continuous questioning in the form of, "What is this?", "What does this mean?" initiated thoughts and ideas. Summary notes were made in the margin of the transcript. These notations formed preliminary codes. Keeping in mind these codes had emerged from the first transcript, the process was applied to other interview transcripts with the idea of determining similarities and differences. This first level data analysis produced open codes that established tentative categories and properties. Recorded list of codes were then were placed on an initial master lists. A coding journal was initiated by way of an audit trail. This was deemed necessary as changes to original lists, resulting from combining or deleting codes on the basis of similarities or differences, necessitated tracking. Data from observations and documents were subjected to similar processes of analysis.

Once all the data was coded, a second layer of analysis was conducted. In order to determine relationships, axial codes were developed and tentative propositions about practice emerged. The paradigm model, in conjunction with open and axial coding of data, enhanced the search 
for patterns and groupings that denoted practices. What followed, once again, involved sorting and deciding which data, categories and subcategories were established and which required moving and reconstructing as new perceptions, insights and understandings emerged. Selective coding established the core and causal properties of capacity building.

As the analysis proceeded, an analytical framework or 'map' emerged (see Figures 1 to 5). The analytical constructs inherent in the framework relate to the analysed data. The framework, sequentially and cumulatively structured, captured the dynamism and complexity of capacity building within this school setting. For example, an examination of Figure 1 reveals the positioning of vision as a core category and its links to practice. Causal properties of school culture, stakeholders as change agents, professional development and practice surrounds vision and substantiates its importance.

\section{Validity and reliability of the data}

In all forms of qualitative research, the need to establish authenticity is paramount. To ensure the findings from this inquiry met internal validity, external validity and reliability requirements, two sets of criteria were proposed: The trustworthiness criteria of credibility, transferability, dependability and confirmability (Guba \& Lincoln, 1994, in Denzin \& Lincoln, 1994) and the authenticity criteria of fairness, namely, "ontological authenticity (enlarges personal constructions), educative authenticity (leads to improved understanding of constructions of others), catalytic authenticity (stimulates action), and tactical authenticity (empowers action)” (Guba \& Lincoln, 1994, in Denzin \& Lincoln, 1994, p. 114).

Trustworthiness and authenticity have been addressed in various ways and as part of the research process. For example, both concepts are addressed by rigorous application of grounded theory methods in data collection, analysis and interpretation. The constant comparative method validates data by comparing: different people in terms of their views, actions and accounts; data from the same person or site at different points in time; incident with incident; data with category; and categories with other categories (Charmaz, 2003).

A traditional take on "triangulation" was also employed to ensure trustworthiness of data. In this inquiry, three forms of triangulation were employed: methodological triangulation with a focus on consistency of findings using different data-collection methods; data source triangulation where consistency of findings related to data gained from different sources but with the use of the same data collection tool; and analyst triangulation where participants verified early interpretations of the findings chapters.

The interpretivist paradigm in which the research was situated, encouraged joint construction of meaning, shared dialogue and on-going participant checks. This position, in itself, provides trustworthiness and authenticity.

Finally, utilisation of grounded methods meant the data analysis itself was less prone to accusations of unreliability. The rigorous method of coding facilitated tracking of information to original text albeit to interview transcripts, observational entries and / or document analysis. Lincoln and Guba (2003) validate this as maintaining an audit trial.

\section{Results}

Capacity building is now mentioned synonymously with school improvement in much of the literature. Research on the topic is, however, limited and generally undertaken at the micro level of school functioning. There is an absence of debate on political, economic and cultural trends with implications for capacity building. This has led to claims that the concept lacks clarity and articulation (Hadfield, Chapman, Curryer \& Barrett, 2004; Hopkins, Beresford \& West, 1998). As such, this research provides a valuable lens for taking a fresh look at what schools do to meet challenges of building capacity and improvement in productive ways. 
Results from interviews, observations and document analysis are organised around the four research questions. With regards to the first research question, a literature review on capacity building is provided prior to explaining defining features of the concept in the case setting. Inclusion of a review (albeit brief) prepares the way for readers to gauge the significance of the research relative to contemporary literature. With respect to the second question, diagrams (Figures 1 to 5) that form the analytical framework and that summarise salient points of attributes and practices are presented first prior to written explanations. Responses to questions three and four are combined to provide a more holistic picture of capacity building for school improvement. The four research questions that underpin the research are:

- How is capacity for school improvement defined - what are its features?

- How do internal school factors - vision, stakeholder activity, culture and professional development - evolve capacity?

- In what ways do external wider societal factors influence the development of capacity?

- What links exist between capacity building and improvement as evidenced in this school setting?

\section{How is capacity for school improvement defined - what are its features?}

Fink (1999), in Deadwood Didn't Kill Itself, suggests that schools with capacity to grow must not only know how to solve problems but also how to identify problems and avoid complacency. Stoll, Bolman, McMahon, Wallace and Thomas (2006) suggest successful educational reform depends on teachers' individual and collective capacity alongside school capacity to promote student learning. Hopkins, Beresford and West (1998) define capacity as 'enabling conditions' that allow 'process' to affect 'product'. Enabling conditions include staff development, enquiry and reflection on progress, involvement of students in the teaching and learning process, distributed leadership, collaborative planning and co-ordinated schoolwide activity that establishes coherence. Despite such definitions, Hadfield, Chapman, Curryer and Barrett (2004) suggest many practitioners consider 'capacity' and 'capacity building' foreign terms. Furthermore, researchers are only just starting to query: What important competencies, abilities and attitudes better manage and sustain improvement? What is the school's current potential to improve?

An expanded perspective of school capacity building, as advanced by Goodman, Baron and Myers (2005), relates to building community capacity. Based on empowerment or enhancement theory, these authors advocate that people (parents / caregivers) can change conditions provided they have access to appropriate knowledge. Gold, Simon and Brown (2005) note parent communities with self-efficacy are better able to combat the demands placed on them by those in positions of power. Community capacity creates political will that motivates officials to take action. In an era of decentralisation, such arguments hold appeal. However, research in this area of community capacity is limited and what is available pursues a narrow conception of parental involvement in, for example, voluntary assistance in schools (Driscoll \& Goldring, 2005).

Capacity building is difficult to conceptualise. Data from this study suggests that capacity building for school improvement is time and context dependent. Its conceptualisation is unique to setting. The results indicate that capacity building for school improvement is a response to meeting individual, collective and systemic needs in ways that sustain equilibrium while moving in the direction of improvement. Attributes inherent in its construction are vision, stakeholders as change agents, school culture and professional development. The main practices are: knowledge production and utilisation; switching-on mentality; and division of labour: roles and responsibilities. From attributes and practices emerge four themes of situated activity, connectedness, leadership, governance and management and outcomes. Attributes, practices and themes explain capacity building for school improvement in this setting. The confluence of these contributing factors enables tensions and needs of context to 
be managed in ways that ensure equilibrium of people, school and system while moving in the direction of improvement.

\section{How do internal school factors - vision, stakeholder activity, culture and professional} development - evolve capacity?

In this section, the four attributes of vision, stakeholder activity, culture and professional development and resulting practices that enhance capacity building are presented utilising diagrams that, as signalled earlier, compose the analytical framework. Written explanations follow accordingly.

Vision

Figure 1

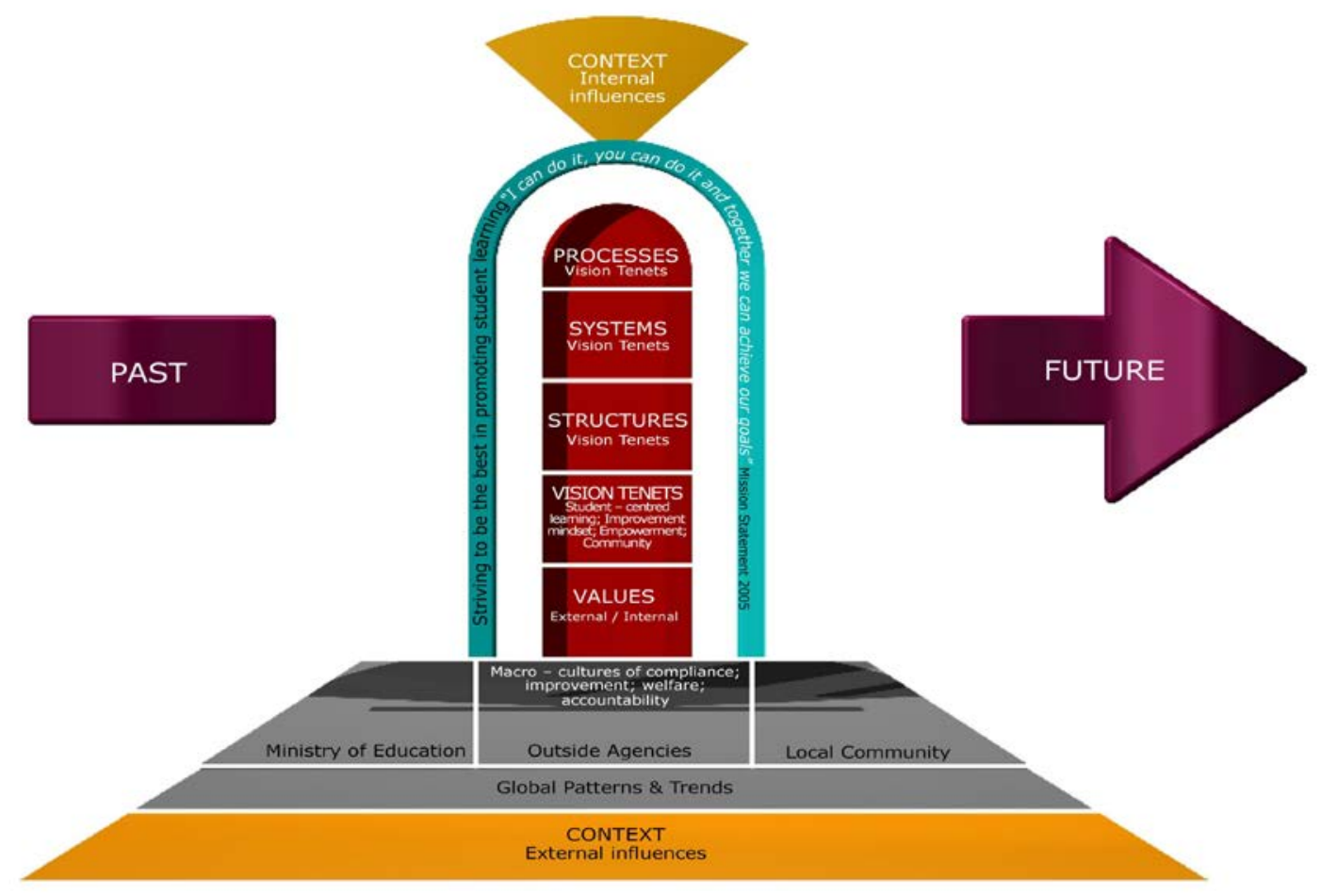

The research demonstrated that vision was the core category enhancing capacity building for school improvement. In brief, the vision is shared, aligned with legislative requirements and staff, students' and parents' / caregivers' needs and aspirations. As captured by Figure 1, its four main tenets of student centred learning, empowerment, community and improvement underpin structures, systems and processes evident in the school. Collective purpose and passion for goal achievement are expressed and enacted in accordance with the four tenets student centred learning, an improvement mind set, empowerment and community. School participants describe the vision as contagious, creating a groundswell of support to the, striving to be the best in promoting student learning vision ideal.

Purpose, accompanied by shared language, promotes common messages and shared meanings. People talk about the vision, use the same language in conversations and believe in the inherent ideals as this comment implies, "It's not about having messages but ensuring that everyone is getting that same message. Everyone is working towards those goals". From a position of common messages and shared meaning, coherence ensues. Coherence, witnessed as ways of working together, agreed expectations and practice consistency facilitates a unified approach to building capacity for school improvement.

Working towards vision involves translating the vision ideal into workable blueprints as recorded in strategic plans. Such documents draw on collective stakeholder input towards 
setting goals and action steps towards goal achievement. A strong focus on expectations and detailing what this means in practice makes improvement easier to manage. Efficiency and effectiveness in working towards vision is promoted.

Practices that support vision implementation also promote its buy-in. For example, strategic plans not only record future directions but also are accountability tools that attest to progress made. They generate professional dialogue around the key tenets of student centred learning, an improvement mindset, empowerment and community. Such engagement affirms and increases stakeholder commitment to overall vision direction and attainment.

Stakeholders' role in vision conceptualisation, transmission and evolution engenders collective activity around doing the best for this school and its stakeholders. External and internal sources of influence impact on vision conceptualisation. In vision transmission and evolution, school stakeholders, "regularly re-look at it" and "re-looking" at vision leads to its modification in line with changing internal and external conditions. For example, one participant noted, "Well last year we did a literacy review. We discussed the results at a staff meeting... We looked at those results. We discussed the positives and the negatives. Where we needed to pick up and where our focus needed to be for the future". Processes of evolution keep the vision alive and current. A 'readiness' or 'preparedness' for change ensures school processes, systems and structures are primed to meet new demands. Such qualities are crucial in building capacity for improvement.

\section{Stakeholders as Change Agents}

Figure 2

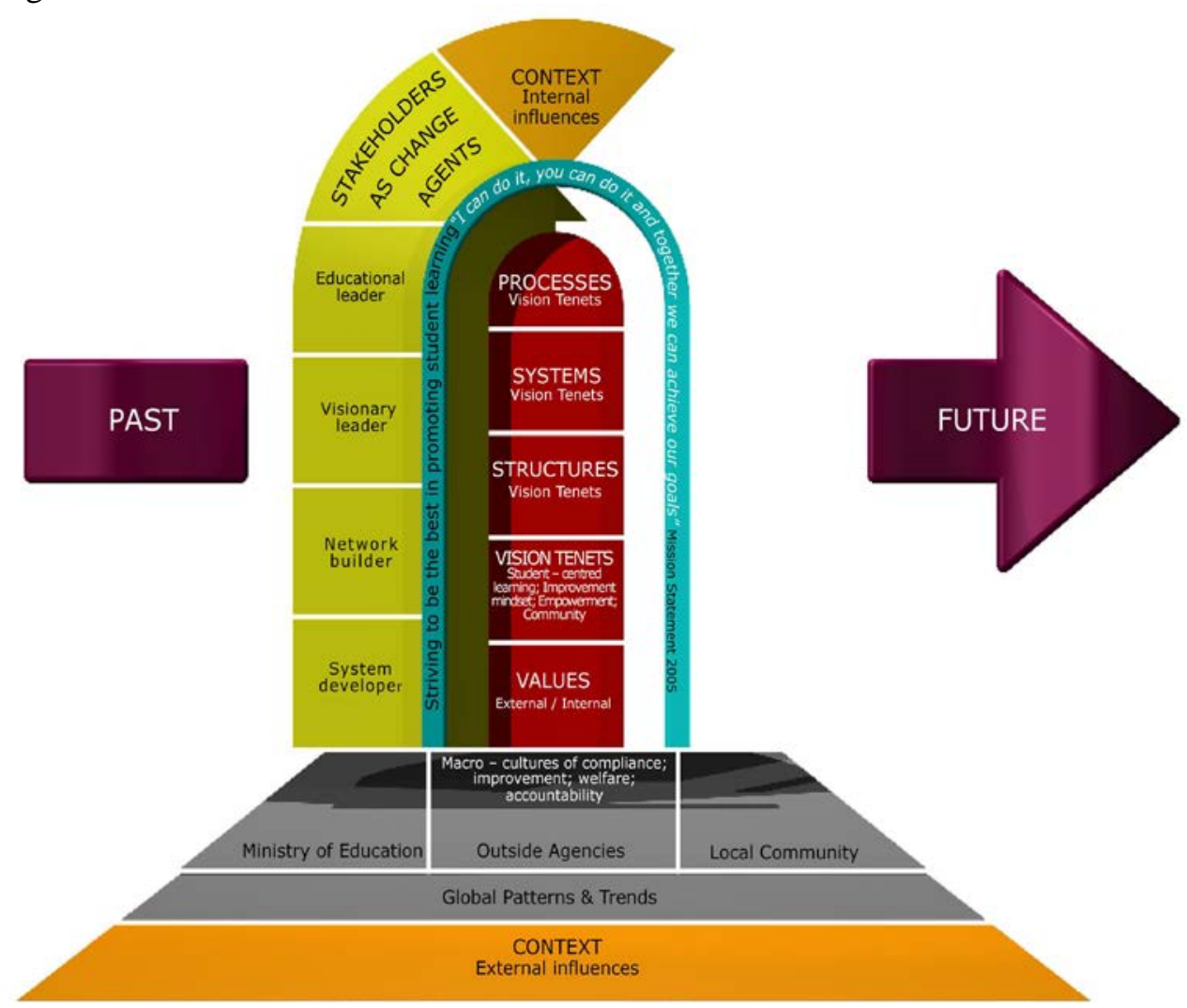

Capacity building for school improvement is concerned with change and management of change. All change has a tendency to disestablish equilibrium and increase uncertainty as new 
ways of doing things are required. Here the concept of school stakeholders ${ }^{13}$ as change agents becomes important. Data from this study suggest that this school's ability to manage change necessitates all its stakeholders working as change agents. As captured by Figure 2, stakeholders serve as educational and visionary leaders, network builders and system developers. The stance they pursue is best explained as appreciating what someone else has to offer and working in ways that consider individual, collective and systemic needs. As change agents, stakeholders work in teams to build individual, collective and systemic capacity. School stakeholders are not prepared to adopt a reactive stance to external and internal challenges of change. Their actions suggest they scan the environment for signs of change and consider ways to make systemic adjustment and modifications in line with vision. Responses are not knee-jerk reactions but strategically implemented through plans that allow time for communication and which brings others on board. In terms of systemic development, challenges at the internal / external interface receive considerable attention. Change is reasoned as being forever present but managed to build capacity for school improvement.

\section{School Culture}

Figure 3

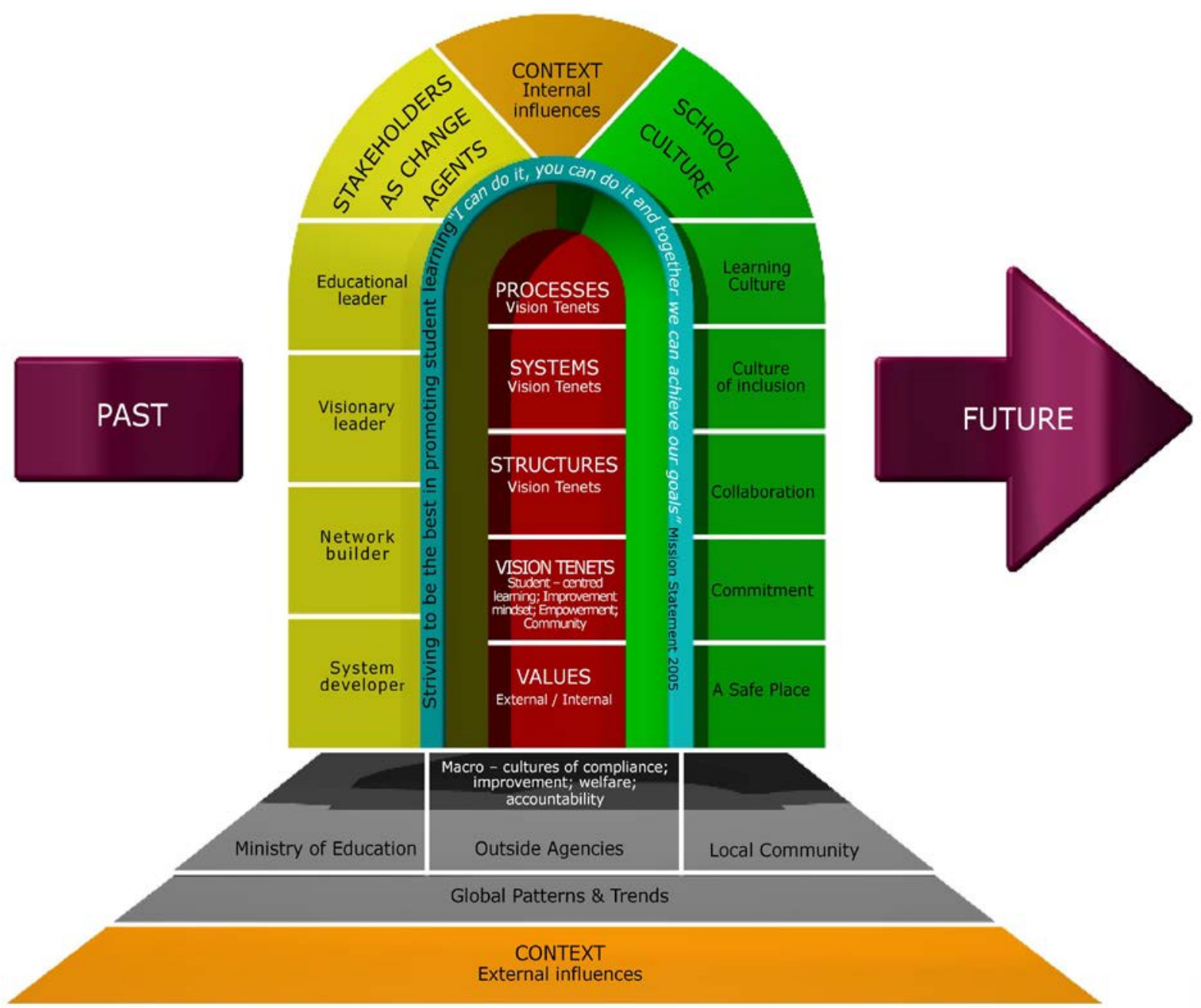

Culture has a major impact on people and school related activities. In this school, there is acknowledgement of diversity and a willingness to incorporate all stakeholders from different

\footnotetext{
${ }^{13}$ School stakeholders is an inclusive word that collectively encompasses the following groups of people: principal, senior managers, teachers, auxiliary staff, students, parents and Board of Trustees representatives.
} 
ethnic groups in creating an inclusive, professional learning community. Here, being part of a 'family' means the school is considered supportive, inclusive and empowering of all its stakeholders.

Figure 3 captures the essential hallmarks of this school's culture. Cultural hallmarks, such as, a learning culture, inclusion, collaboration, commitment and safe place reduce anxiety often associated with change. The potential for conflict and misunderstanding is minimised because of the stance taken in collectively maximising curriculum delivery, building relationships and encouraging home-school partnerships. Working towards greater parent / caregiver involvement in school life is an attempt to counteract some of the barriers ethnic minority groups face. This school's culture is influenced by macro and micro cultural norms, school practices, history and people associated with the school. A blending of all creates a fertile ground within which to construct and enact processes that build capacity for school improvement.

\section{Professional Development}

Figure 4

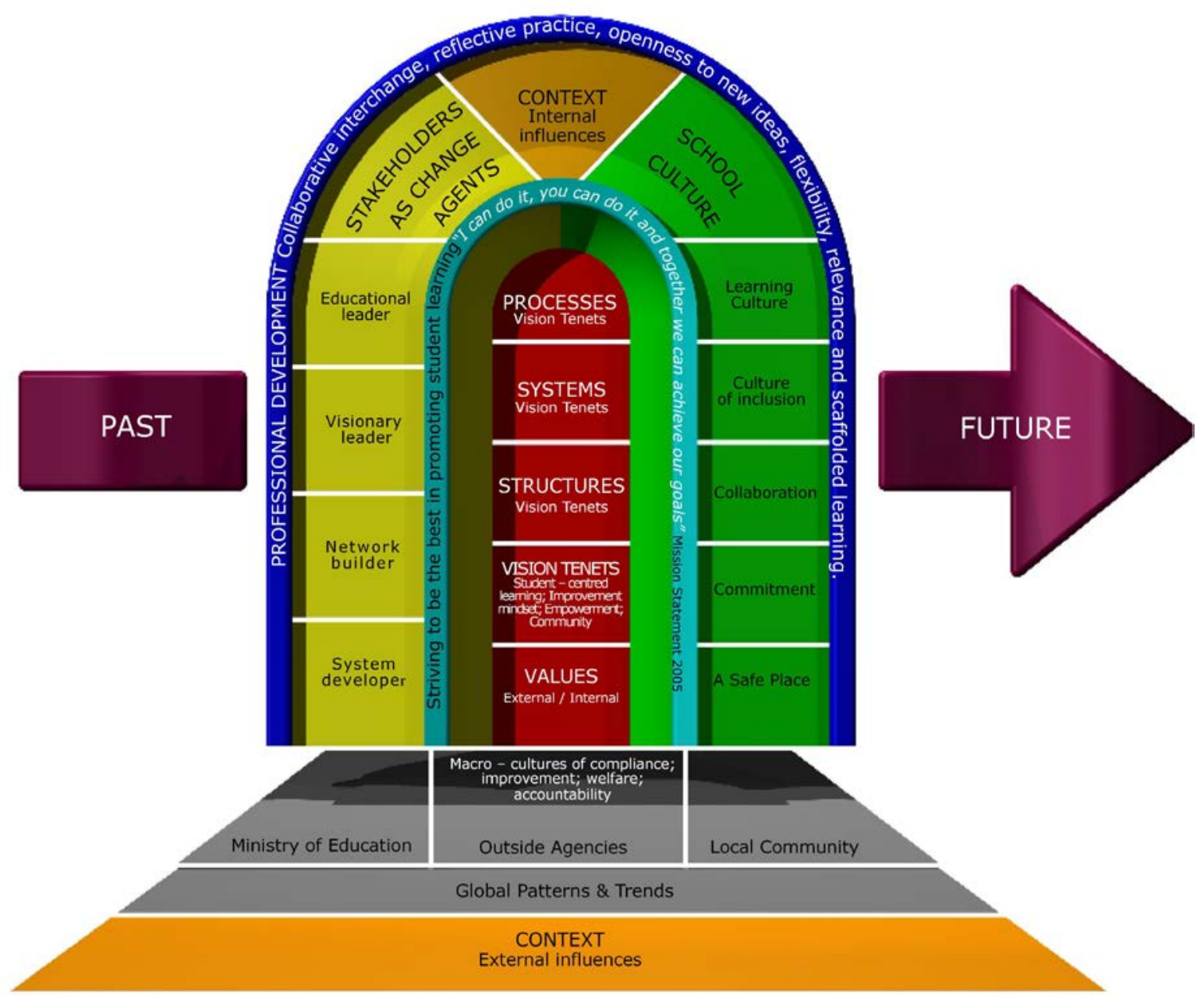

Professional development is situated at the external / internal interface of the capacity building analytical framework as shown Figure 4. Its main components are: collaborative interchange of information; reflective practice; openness to new ideas; flexibility; relevance; and scaffolded learning. The position at the interface is justified by data indicating that professional development is both internally and externally sourced. The result of internal / external connections translates to processes of knowledge production and utilisation that 
enhance capacity building for school improvement. Professional development is layered, continuous, complex, and intricately interwoven into the fabric of the school, that is, its school culture. It is inclusive of all school stakeholders. Professional development facilitates the development of a community of learners and leaders and helps build individual, collective and systemic learning capabilities.

\section{Practices}

Figure 5

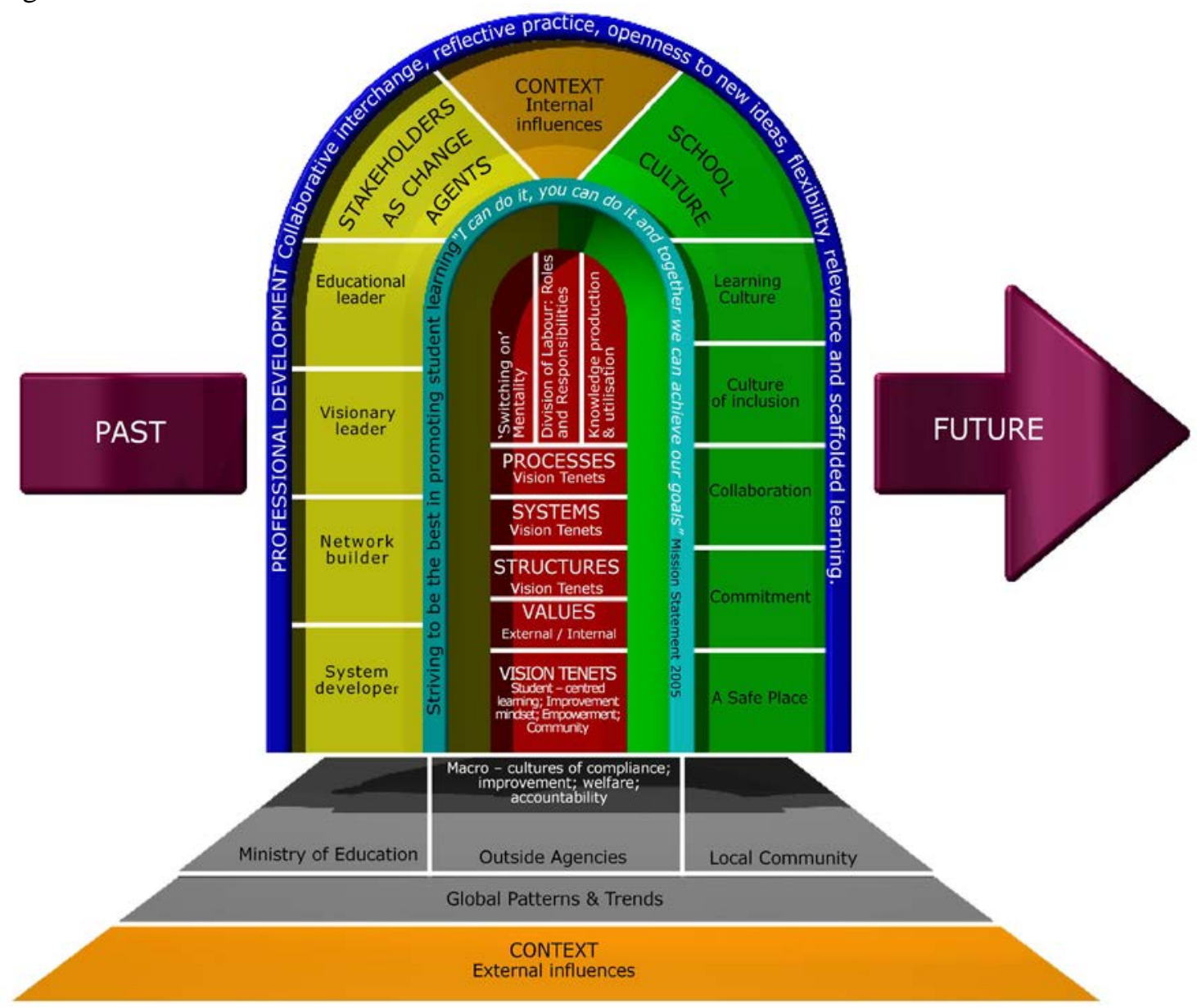

Data on practices that contribute to capacity building have established links to attributes. As Figure 5 captures, the three main practices of knowledge production and utilisation, division of labour into shared roles and responsibilities and 'switching on' mentality are situated at the hub of the capacity building framework. Although the decision was made to highlight and present the evidence on each practice separately, it must be noted that the synergistic qualities of all are essential in building capacity. Practices of knowledge production and utilisation engender connectedness through learning. Division of labour: roles and responsibilities focus on workplace structures that encourage team work. 'Switching on' mentality is what builds this school's 'heart'. 'Switching on' practices highlight the interpersonal mode of relationships.

In this site, knowledge ${ }^{14}$ is perpetually being created and utilised in the generation of new ways of doing things that meets stakeholder and school needs better. Knowledge production

\footnotetext{
${ }^{14}$ Knowledge is defined as information gleaned from professional input external or internal in source. External input is generally associated with course attendance or outside agency / Ministry of Education
} 
and utilisation serves a predictive purpose ${ }^{15}$. Knowledge production and utilisation systems, processes and structures are created on the basis of vision that secures a sense of direction and purpose; school culture which provides a suitable platform for enacting performance; professional development that facilitates learning; and stakeholder activity that promotes knowledge acquisition, distribution, adaptation and usage. Knowledge production and utilisation has individual, collective and systemic dimensions which enhance learning, goal achievement and capacity building.

Formal workplace structures and networks promote division of labour: roles and responsibilities. Their link to the school's vision enhances collaborative decision-making, value debates, vision implementation, monitoring of quality, accountability and a working community ethos. Power structures of a flat management type mean senior managers, school board members, teaching staff, support staff and parents / caregivers work together for the betterment of the school and its stakeholders. School systems and ways of working encourage shared roles and responsibilities whereby, as one participant recalled, "channels of communication and procedures are in place and people know exactly where they stand and what's expected...clarity, expectation, follow through are expected".

A 'switching on' mentality, so prominent in this school, endorses collaboration and collegiality. This school is seen as a place with a 'heart' that beats strong. It is a place where people want to be as this comment implies, "I personally have found this to be one great place to be. It would probably take me a long time before I left"; "It's just this living breathing thing that occupies a space in my heart". Reasons for 'wanting to be here' result from:

- People feel they are listened to; their voices are heard. The atmosphere builds trusting relationships as this comment implies, "you are allowed to say what you want to say or say how you feel and they're not going to shout you down";

- The stance adopted is action orientated with openness to new ideas as this example suggests, "We were talking about the old hall and saying it is really small. So it took some time. They were planning it for twelve years. But it is happening now" ;

- Collaboration is endorsed and defined by one participant as, "The thing is all the leaders, the team leaders what they do is they try to ask other teachers their opinion, for example, about books that they need to buy" ;

- Open, transparent communication is practised and is defined as, "When things are happening they do tell us and so all of us know the same thing" ; and

- Integrity is valued. According to one participant, "I have found that the (principal) and (deputy principal) take things on board...so its lots of practice before they say things and they do it and they show us and they say see this is how it can be done".

From a detailed examination of attributes and practices, four main themes emerge that underscore capacity building for school improvement (see Figure 6). The four themes of situated activity, connectedness, governance, leadership and management and capacity outcomes are discussed in line with the third and fourth research questions.

In what ways do external wider societal factors influence the development of capacity? What links exist between capacity building and improvement as evidenced in this school setting?

Situated Activity

Literature suggests schools are nested within layers of society (Dantley, 2005). They are interconnected (Hargreaves \& Fink, 2006) and operate as open systems (Lam \& Punch, 2001;

association. Internal input is associated with collecting and analysing evidence of stakeholder and system need gained from systems such as reviews and appraisals.

${ }^{15}$ Predictive purpose is taken to mean the ability to determine future pathways of action from evidential data and processed information gathered, analysed and modified to site specification. 
Pristine \& Nelson, 2005) influenced by macro and micro cultural norms. In New Zealand, macro cultural norms of accountability, compliance and improvement align with Ministry of Education's aims of raising student achievement and reducing disparity (MOE, 1999, 2004; Alton-Lee, 2003). Key forces underpinning the aims are: responsiveness to diverse cultures and a wide range of needs and aspirations; globalisation; the impact of technology and information; and development of a knowledge-based economy. The Ministry's emphasis on achievement is targeted at: effective teaching for all students; family and community engagement in education; and development of quality providers (MOE, 2004). A wide range of legislative mandates ${ }^{16}$ ensure aims are met in practice. Government policy demands schools meet accountability, compliance and improvement legislative mandates. Alongside socio-economic factors, such requirements influence what happens in practice.

Data from this research suggest the school complies with Ministry and local community requirements. Capacity building for school improvement is a considered response to macro and micro calls for accountability, compliance and improvement. Macro and micro contexts are not static states of 'being' but they change in relation to acts of 'doing'. Shifting tensions and opportunities for growth and development impact on the work of stakeholders; capacity building results from minimisation of limitations and maximisation of opportunities to benefit the school and its stakeholders. The importance of situatedness in enhancing capacity cannot be dismissed.

Data indicate the following characteristics of 'situatedness' as important. First, vision construction, implementation and renewal underpin all capacity building for school improvement activity. Furthermore, vision construction is an act of 'deliberate choice' in response to macro and micro cultural values and challenges of context. In this setting, a socially constructed vision is articulated as striving to be the best in promoting student learning. It is supported by four tenets of student centred learning, an improvement mindset, empowerment and community. The vision balances external demands with needs of the school and its stakeholders. Second, vision espousal and enactment set parameters for managing tensions; that is, minimisation of limitations and maximisation of opportunities to benefit the school and its stakeholders. Third, capacity building for improvement has historical connections, current applicability and a futuristic outlook. The construct is unique and situated in context.

School stakeholders define capacity building for improvement as a situated activity with corresponding outcomes. For example, at the time when the school was reported to be in crisis, outside agencies worked alongside the principal to ensure organisational stability. Capacity building, in this early phase of improvement, necessitated:

- The principal prioritising and enacting systemic solutions in response to need;

- Utilisation of outside 'experts' to improve practice;

- Creation and reflection of an evidence base for inquiry into practice;

- Construction and implementation of school vision;

- Creation of opportunities to engage in professional talk; and

- Openness to new ideas with growing motivation to learn and stay current.

External agency input in capacity building related to:

- Input of content knowledge and pedagogical skills;

- Initiation of reflective practice through professional dialogue;

- Collective sharing of information and generation of a 'working' team ethos; and

- Establishment of consistency of practice through:

o Focused attention on vision;

\footnotetext{
${ }^{16}$ See for example: Ministry of Education (1993a) The National Education Guidelines (1990) and Ministry of Education (1993b) The New Zealand Curriculum Framework (1993).
} 
o Systemic modification and adaptation to situational need; and

o Development of infrastructures to support the work of staff.

In the initial phase of school improvement, capacity building outcomes related to achieving organisational stability through: buy-in to a common sense of direction; development of a positive, working school culture; and creation of a safe learning environment. Outside agency representatives were change agents as site-based knowledge, expertise and skills were lacking. As signalled previously, capacity building for school improvement reflects action at a particular time and in response to unique political, cultural and socio-economic drivers. With continued drive for school improvement from the principal and newly appointed deputy principal, an internal capacity for self-governance and self-management strengthened. This was largely due to senior managers' knowledge, skills, expertise, collaborative strategies and networks of support in advancing the work previously accomplished by outside agencies. A working culture, opportunities for professional development and staff enthusiasm for change altered school conditions. Capacity building outcomes expanded to include:

- Building teacher confidence to take risks;

- Pushing the boundaries of practice through engagement in new learning;

- Raised teaching and learning expectations;

- Participation in collective pursuit of capacity building;

- Increased responsiveness to demands for change (external and internal);

- Development of a collaborative, working and learning environment inclusive of parents / caregivers;

- Ongoing systemic support in response to altered school / stakeholder need; and

- Sustainment of a positive school image.

Data indicate that no single definition captures the essence of capacity building for school improvement over time. A lack of uniformity is ascribed to uniqueness of individual perception, time, situational constraints, opportunities and multiplicity of tasks requiring attention. Capacity building is undoubtedly the result of situated activity; a response to sitebased demands for change that involves:

- Construction of a grounded, shared, evolving vision;

- Vision informed practice; and

- Management of tensions - minimising limitations and maximising opportunities to benefit the school and its stakeholders.

\section{Connectedness}

Connectedness is the development of meaningful relationships in pursuit of activities that 'promote student learning'. Connectedness is a multi-dimensional concept that emerges when all interested parties (Ministry of Education, outside agencies, businesses, parents / caregivers, staff and students) support the school's vision. Internal connectedness is achieved through practices of knowledge production and utilisation that generate learning; a 'switching on' mentality that reinforces norms of how things are around here; and division of labour, shared roles and responsibilities that advances team work - collaboration in getting things done. Data reveal an inevitable connection to The National Education Guidelines because of statutory links that connect the school's vision to inherent guidelines contained in the National Education Goals (NEGs) and the National Administration Guidelines (NAGs). School documents, systems, processes and structures promote external / internal links that have beneficial flow-on effects in building capacity.

Connectedness at the external / internal interface occurs on several levels with benefits to the school and its stakeholders. First, addressing mandated requirements means the school meets health and safety standards (ERO, 2005). In addition, implementation of new legislation sustains a 'safe place' ethos that participants note is conducive to learning. Second, the Ministry of Education, outside agencies, tertiary institutions, schools and other community 
groups serve as catalysts for change through provision of new information. Opportunities to participate in Ministry contracts and buy-in of outside agency support for curriculum and pedagogical development is reported as advancing individual, collective and systemic 'working' knowledge capacities. Similar claims are made of associations with professional networks. Participants claim outside knowledge raises standards of expectations, motivates learning and precipitates new, more effective ways of doing things. The value of outside connections in improving teacher content knowledge and pedagogical skills is acknowledged by various authors (see for example, Symes, Jeffries, Timperley and Lai, 2001). Third, connectedness with the Ministry, outside agencies and community groups bolsters the school's 'working' resource base.

In this site, internal / external connectedness achieve 'crafted coherence' (see Honig and Hatch, 2004) where, "ongoing investments in the institutional capacity of schools and district central offices to engage in practices...help schools manage multiple external demands productively" (p. 27). Crafting coherence is a connected, situated activity as the school seeks assistance and exercises control over its improvement trajectory. School stakeholders negotiate scope of support needed to achieve goals. In other words, connectedness and situatedness promote meaningful relationships in activities that build capacity to 'promote student learning'.

\section{Governance, Leadership and Management}

Capacity building for school improvement requires effective governance, leadership and management. Governance, leadership and management inevitably means meeting accountability, compliance and improvement demands as stipulated in The National Education Guidelines. Observations and participants' responses indicate stakeholders are aware of their roles and responsibilities aligned to the NEGs and the NAGs and to each other. They manage calls for accountability, compliance and improvement as individuals and within a collective to maintain organisational equilibrium and advance improvement. Stakeholders work as change agents to build capacity for improvement. As change agents they exercise:

- Visionary leadership;

- Educational leadership;

- Network building; and

- Systemic development.

Stakeholders are guardians of the vision. As vision guardians, they perpetuate its construction. Their input keeps the vision alive and grounded in reality. Vision renewal is not imposed but created from practice; not isolated but part of everyday life; and planned in terms of initiating growth and development. The I can do it, you can do it and together we can achieve our goals statement enhances collective buy-in to vision. Stakeholders are forever mindful of avoiding the 'blunting of vision' (Barth, 1990) effect with respect to tensions of context.

Blunting of vision is minimised by working towards vision in thoughtful, planned and collective ways. Stakeholders ensure that vision ideals permeate through all levels of practice to promote student learning. Vision is embedded in this school's culture and its implementation monitored and reinforced through governance, management and leadership activities. Collective construction of vision raises communal consciousness to its implementation. Stakeholders' espousal and enactment of values and beliefs create cultural hallmarks that assist in vision implementation. Internalisation and continued enactment of cultural hallmarks make stakeholders, in governance, leadership and management capacities, agents of change recreating what they believe to be moral and ethical practice.

All stakeholders provide educational leadership. The board endorses professional development through allocation of funds in accordance with stated goals contained in strategic plans. Staff drive the professional development agenda. Their engagement in 
individual and systemic reviews creates base line data from which to construct learning trajectories that correspond to individual, collective and systemic need. Staff engagement in the monitoring of professional development increases their professionalism. The culture that emerges is best described as a professional learning community. A community of educational leaders and learners enhances capacity building for school improvement.

In this school, many forms of formal / informal and internal / external networks exist to support community life. Participants claim that a flat management structure promotes networking and team work. Observations of practice suggest that team arrangements serve as powerful structures to push for capacity building. Networking and team work in governance, leadership and management roles and responsibilities offers:

- Access to information from which to engage in knowledge creation;

- Access to systemic and collegial support;

- Engagement in processes of participatory decision-making;

- Opportunities to consult and negotiate future plans as a collective;

- Engagement in value debates;

- Ability to meet accountability, compliance and improvement demands in effective, collective ways;

- Opportunities to attach meaning and purpose to work;

- Opportunities to solve problems and deal with conflict in creative ways; and

- Opportunities to build and sustain coherency in accordance with purpose - striving to be the best in promoting student learning.

School stakeholders with governance, leadership and management roles and responsibilities are system developers. Systemic development is achieved through participatory, distributed practice. This is a school where school structures are 'regularised' to promote sharing of practice (Gronn, 2002). The overall school structure promotes teamness as preferred ways of working but not at the expense of professional autonomy. Work here is, as Sayles (1964) describes it, "coordinated and undertaken interdependently" (p. 115). Individuals contribute to a collective knowledge base that is of pragmatic use in systemic development. A systemic approach values both individual and collective contribution to school capacity building for improvement.

Systemic development requires leadership qualities of governors, leaders and managers which are transformational (see for example, Northhouse, 2004) and post-transformational (see for example, West et al., 2000; Day, 2000; Sergiovanni, 2006). In addition, distributed leadership practices, as defined by Gronn (2002), and management practices, as purported by Dalin (2005) and Hallinger and Snidvongs (2005), are required. The demand for inclusive approaches to governance, leadership and management (see for example, Furman \& Shields, 2005; Shields \& Sayani, 2005; Lindsey, Roberts \& Cambell Jones, 2005) coupled with calls to develop a professional learning community (see for example, Barth, 1990; Bolman et al., 2005; Stoll et al., 2006) are also frequently raised. Observation of practice suggests that a systemic approach receives the attention of stakeholders in performing the multitude of tasks expected of them. School systems, processes and structures ensure decisions made collectively serve the best interest of the school and its stakeholders. A systemic approach offers best 'fit' with conditions of context (external and internal). Systemic development draws on all stakeholders' support in sustaining school improvement. Collective input assists in the management of tensions and in the building of capacity for school improvement.

\section{Outcomes}

Outcomes are inherent in capacity building activities. Outcomes are traceable to the vision statement, striving to be the best in promoting student learning, and, invariably, to the NEGs and the NAGs. Participants' comments indicate that being 'the best' is multi-dimensional. For example, it draws on: 
- Working towards vision and support of the four tenets;

- Provision of a balanced curriculum that addresses the diverse needs of students;

- Development of a professional learning culture inclusive of all stakeholders;

- Creating practices in support of biculturalism and multiculturalism;

- Competing favourably with other schools in promoting roll growth;

- Effective management of tensions;

- Promotion of this school as 'school of choice';

- Productive partnerships between staff and parents / caregivers;

- Connectedness among all interested parties in doing what is best for the school; and

- Systemic coherence and consistency of practice.

Data indicate that capacity building has both process and product outcomes related to specific practices of knowledge production and utilisation, switching on mentality and division of labour into shared roles and responsibilities. Commonly associated outcomes for all practices include:

- Focused attention on promoting student learning;

- Reinforcement of the tenets in support of the vision ideal;

- Doing the ordinary things better;

- Maintaining a sense of equilibrium coupled with that of improvement;

- Building on past endeavours to meet current and future needs; and

- Promoting this school as a safe place.

Outcomes are a necessary part of organisational existence for both legislative and internal reasons. Findings from this study indicate that this school has robust systems, processes and structures that monitor, collate, analyse and utilise data in improving practice. Outcomes related to student progress are measured and reported in accordance with mandatory requirements. This school's philosophy of 'promoting student learning' means that all aspects of organisational life are scrutinised in an attempt to improve practice. To authenticate effectiveness of vision, school culture and professional development in improving practice that is more than just an account of 'feel', attention is paid to staff accounts of their personal and professional growth. It is in the telling of stories and collaborative interchanges of dialogue that change of practice gets acknowledged. As sustainability of improvement is important, judgements calls that record altered habits and beliefs and movement to more effective ways of doing things are gained through talking to people and:

- Observation of practice (senior management and peers);

- Individual appraisals;

- Self-monitoring of practice; and

- Systemic reviews that generate a collective data base.

The final diagram, Figure 6, captures and explains the way attributes, practices and themes contribute to capacity building for school improvement. Figure 6 presents, in diagrammatic form, a capacity building for school improvement conceptual framework that explicates the emerging substantive theory evidenced in this site.

A Capacity Building Conceptual Framework: Attributes, Practices and Themes Figure 6 


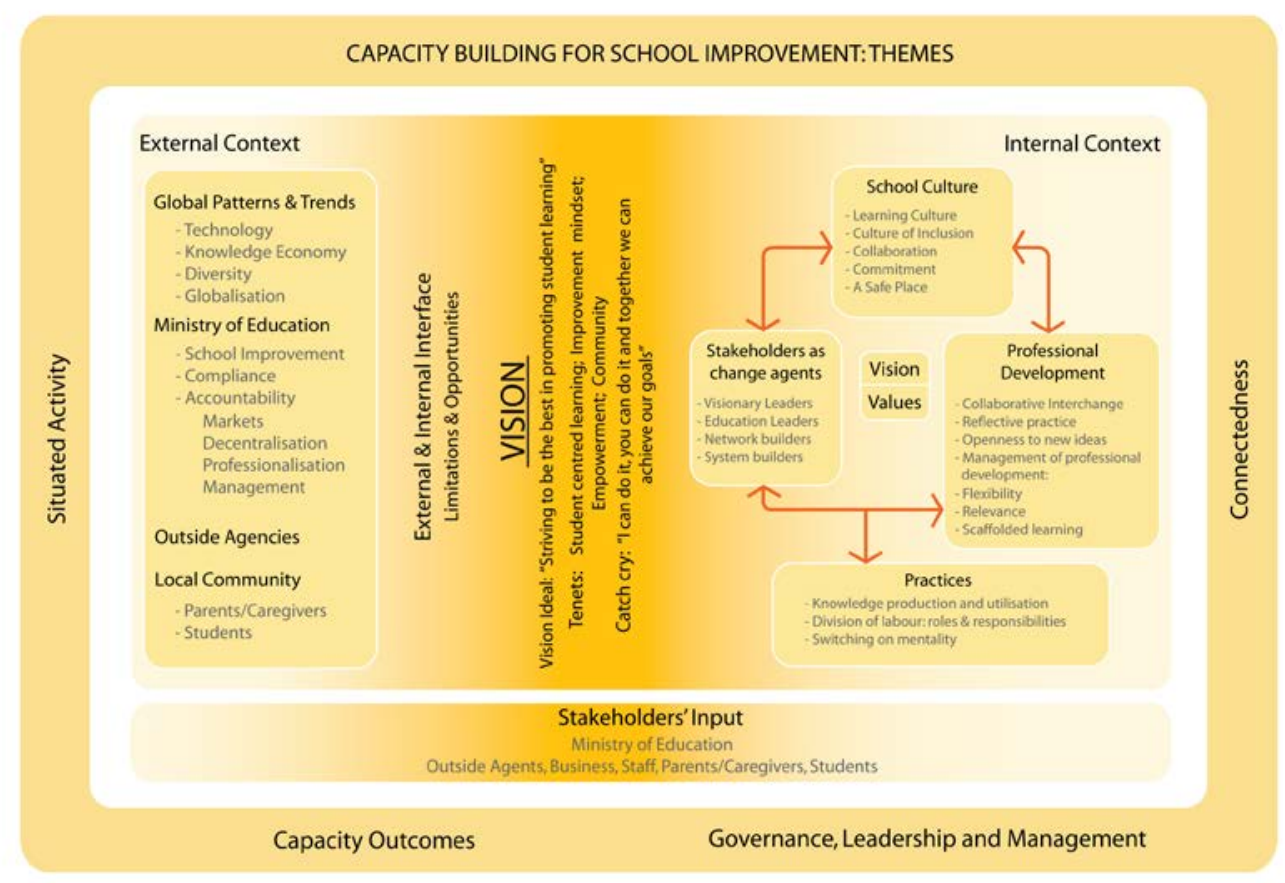

\section{Conclusion}

Capacity building for school improvement is a difficult concept to define. Hopkins et al. (1998) define it as enabling conditions that allow process to affect product. Fullan (2005) suggests the construct relates to development of collective ability to act together to bring about change. Stoll et al. (2006) link the construct to sustainable school improvement best achieved in professional learning communities.

These definitions do not fully position or capture the complexity of the construct in context. Context in itself is multi-dimensional, requiring deconstruction. For example, New Zealand schools operate within external and internal contexts influenced by society and a national education system. Macro cultural norms of accountability, compliance and improvement and socio-economic location factors influence and continually shape what happens in schools. They determine what is of value. Macro and micro values provide a framework within which schools must construct their vision. This school's vision is an act of deliberate choice encapsulated in a powerful message of striving to be the best in promoting student learning. It is supported by four tenets of student centred learning, an improvement mindset, empowerment and community. The way this school defines and works towards making its vision a reality creates a distinctive brand of capacity building for school improvement.

A substantive theory of capacity building for improvement highlights vision at the core with direct links to stakeholders as change agents, school culture and professional development. Vision, stakeholders as change agents, school culture and professional development are attributes that determine the nature of practice: knowledge production and utilisation; division of labour: roles and responsibilities; and a 'switching on mentality'. From a detailed examination of attributes and practices, the four main themes of situated activity, connectedness, governance leadership and management and outcomes underscore capacity building for school improvement. The following implications for policy and practice are raised as a result of this study.

\section{Implications for Policy}


The results indicate that establishment of strong networks among Ministry, outside agencies and school stakeholders is crucial for sustainment and further evolvement of capacity building for improvement. For example, networking assists in the minimisation of limitations and maximisation of opportunities to promote capacity. It is important that schools, in their drive to improve, gain and utilise the support of the Ministry and outside agencies to achieve successful outcomes. Networking at both micro and macro level of practice must be acknowledged as an essential prerequisite to meeting individual, collective and systemic needs.

Networking and a commitment to assisting schools on an individual basis requires full acknowledgement and support by Ministry of Education officials and outside agencies. In this respect, Honig and Hatch (2004) note, "ongoing processes where schools and central agencies work together to manage external demands" (p. 27) challenge the stereotypical role of policy makers as primary decision makers and this stance needs replacing with one more supportive of schools and the decisions they make. The Ministry and outside agencies need to be open and responsive to suggestions from school stakeholders as to what works in context. A situated, connected response to highly complex issues of improving schools is needed to sustain and strengthen capacity building for improvement.

\section{Implications for Practice}

In light of the results, the school's vision is acknowledged as influencing practice. The vision engenders passion, purpose and movement in the general direction of improvement. Working with vision is seen as promoting purpose driven action that buffers and protects the school from undue demands for change. Although the power of vision is seen to be central to the capacity building process, deconstruction of the ideal and expression in practical terms is necessary to achieve 'blueprints' for action and meaningful work. At the practical level, school boards and personnel need to consider how their documents, policies, procedures and management systems connect to the vision and corresponding values. Construction, implementation and evolution of vision in line with changing conditions needs thoughtful consideration to develop congruence between philosophy, values, sense of purpose and practice.

The current educational landscape presents major challenges for school stakeholders desirous of improvement. For example, the Ministry's drive for accountability, efficiency and effectiveness is regarded as necessary but also a source of pressure and frustration. Results from this study indicate that school stakeholders ensure accountability measures are met not only in terms of compliance, but also in keeping with their vision, the striving to be the best in promoting student learning ideal. School stakeholders adopt a critical stance concerning what is important. Whilst policy and legislative mandates require fulfilment, the philosophy that binds and drives the capacity building process is the school's vision. The message for all schools is to retain and adhere to their vision as a catalyst for reform without dismissing legislative requirements. Honouring one's vision and, at the same time, working within a collective national vision constitutes an important aspect of capacity building for improvement.

There is a need for each school to ensure that its core philosophy, values and beliefs are fully integrated in school life to form a culture supportive of improvement. Contradictions between what is articulated and enacted may serve to negate any or all capacity building measures for improvement. For boards of trustees and staff this means, for example, evaluating the culture of the school, the quality of interpersonal relationships and the degree to which both contribute to capacity building for school improvement. If school stakeholders are collectively responsible for assisting in the capacity building process, then it follows they be afforded regular opportunities to 'come on board'. A system that enables stakeholders to learn more about school operational processes, systems and structures builds capacity for improvement from within. 
Professional development that is simply focused on expanding teacher knowledge of classroom practice is not adequate in building capacity for school improvement. Professional development has to contain elements of increasing institutional, collective and individual capacities in terms of knowledge production and utilisation. Collaborative forms of professional development, a situated, layered approach and a learning community culture not only fosters collective stakeholder opportunities to discuss beliefs about teaching and learning, but also gives permission to critique practice, take risks and share in on-going processes of knowledge acquisition and utilisation. The learning that results connects stakeholders to a situation where outcomes align with purpose. Learning, albeit individual, collective and / or systemic, is transformative. Learning creates capacity in context.

Amid calls for improvement at both the micro and macro level of performance, little attention has been given to the crucial role parents / caregivers play in the capacity building process. Results from this study indicate that parents / caregivers contribute much to the process in a variety of ways. For example, parents / caregivers, through the board of trustees, bring a community perspective to matters of governance. Other parent groups, such as, 'Friends of the School' and ethnic groups offer support in terms of fund raising and cultural activities. All activities are pathways that promote situated, connected and focused activity desirous of improvement. If increasing parental involvement and honouring the true meaning of partnership is desirous in the quest for improvement, then a preparedness to critically assess what happens in context promotional of this must exist. Maintaining a critical perspective in the building of authentic home / school partnerships may add to the pressures and tensions already faced, but failure to act perpetuates the myth that is home / school partnership and the true value of partnership fails to be established. The need for further research on the topic is necessary.

\section{Final words}

This paper has introduced attributes, practices and underpinning themes associated with the concept of capacity building for school improvement. The confluence of attributes, practices and underpinning themes enables tensions and needs of context to be managed in ways that ensure equilibrium of people, school and system. This builds capacity while moving in the direction of improvement.

\section{$\underline{\text { References }}$}


Alton-Lee, A. (2003). Quality Teaching for Diverse Students in Schooling: Best Evidence Synthesis. Wellington: Ministry of Education.

Barth, R. (1990). Improving Schools from Within. San Francisco: Jossey-Bass.

Bolman, R., McMahon, A., Stoll, L., Thomas, S., Wallace, M., Greenwood, A., Hawkey, K., Ingram, M., Atkinson, A., \& Smith, M. (2005). Creating and sustaining effective professional learning communities (Research Rep. No. 637). London: DfES and University of Bristol.

Charmaz, K. (2003). Grounded Theory: Objectivist and Constructivist Methods. In N. Denzin, \& Y. Lincoln Strategies of Qualitative Inquiry ( $2^{\text {nd }}$ ed.) (pp. 249-292). Thousand Oaks, CA: Sage.

Clark, J. (1997). Educational Research: Philosophy, Politics, Ethics. Massey University, Palmerston North: ERDC Press.

Dalin, P. (2005). School Development. Theories and Strategies. London: Continuum.

Dantley, M. E. (2005). Moral Leadership: Shifting the Management Paradigm. In F. W. English (Ed.), The Sage Handbook of Educational Leadership. Advances in Theory, Research, and Practice (pp. 34-47). Thousand Oaks: Sage.

Day, C. (2000). Beyond Transformational Leadership. Educational Leadership, April 2000, 56-59.

Denzin, N. K., \& Lincoln, Y. S. (1994). Handbook of Qualitative research. Thousand Oaks, California: Sage.

Driscoll, M. E., \& Goldring, E. B. (2005). How Can School Leaders Incorporate Communities as Contexts for student Learning? In W. A. Firestone, \& Riehl (Eds.), A New Agenda for Research in Educational Leadership (pp. 61-80). New York: Teachers College Press.

Education Review Office. (2000). Multi Cultural Schools in New Zealand. Retrieved January 2, 2007, from http://www.ero.govt.nz

Education Review Office. (2005). Confirmed Education Review Report (school name withheld to maintain anonymity) Retrieved January 2, 2007, from http://www.ero.govt.nz

Elmore, R. (1995). Structural reform and educational practice. Educational Researcher, 24(9), 23-26.

Fink, D. (1999). Deadwood Didn't Kill Itself. Education Management and Administration, 27 (2), 131-141.

Fullan, M. (2005). Leadership \& sustainability. System Thinkers in Action. Thousand Oaks, CA: Corwin Press.

Furman, G. C., \& Shields, C. M. (2005). How Can Educational Leaders Promote and Support Social Justice and Democratic Community in Schools? In W.A. Firestone, \& Riehl (Eds.), A New Agenda for Research in Educational Leadership (pp. 119-137). New York: Teachers College Press.

Glaser, B. G. (1978). Theoretical Sensitivity. Mill Valley, CA: Sociology Press. 
Glaser, B. G. (1992). Basics of Grounded Theory Analysis. Mill Valley, CA: Sociology Press.

Glaser, B. G. (2001). The Grounded Theory Perspective: Conceptualization Contrasted with Description. Mill Valley, CA: Sociology Press.

Glaser, B. G., \& Strauss, A. L. (1967). The Discovery of Grounded Theory: Strategies for qualitative research. New York: Aldine De Gruyter.

Gold, E., Simon, E., \& Brown, C. (2005). A New Conception of Parent Engagement. Community Organizing for School Reform. In F. W. English (Ed.), The Sage Handbook of Educational Leadership. Advances in Theory, Research, and practice (pp. 237- 268). Thousand Oaks: Sage.

Goodman, J., Baron, D., \& Myers, C. (2005). Constructing a Democratic Foundation for School-Based Reform. In F. W. English (Ed.), The Sage Handbook of Educational Leadership. Advances in Theory, Research, and practice (pp 297-331). Thousand Oaks: Sage.

Gronn, P. (2002). Distributed leadership as a unit of analysis. The Leadership Quarterly, 13(4), 423-451.

Hadfield, M., Chapman, C., Curryer, I., \& Barrett, P. (2004). Building Capacity Developing your School. Retrieved January 20, 2004, from http://www.ncsl.org.uk

Hallinger, P., \& Snidvongs, K. (2005). Adding Value to School Leadership and Management. A review of trends in the development of managers in education and business sectors. Paper commissioned for the national College for School Leadership, Nottingham, England.

Hargreaves, A., \& Fink, D. (2006). The Ripple Effect. Educational Leadership, 63(8), 3-21.

Hawk, K., \& Hill. J. (1997). Towards Making Achieving Cool. Some policy implications for student achievement in low decile schools. Paper presented at the NZARE Conference, New Zealand.

Honig, M., \& Hatch, T. (2004). Crafting Coherence: How Schools Strategically Manage Multiple, External Demands. Educational Researcher, 33(8), 16-30.

Hopkins, D., Beresford, J., \& West, M. (1998). Creating the Conditions for Classroom and Teacher Development. Teachers and Teaching: theory and Practice, 4(1), 115 - 141.

Johnson, B., \& Christensen, L. (2004). Educational Research: Quantitative, Qualitative, and Mixed Approaches. Boston: Pearson Education, Inc.

Lam, Y. L. J., \& Punch, K, F. (2001). External Environment and School Organisational Learning: Conceptualising the Empirically Neglected. Leadership and Learning, 29(3), 2839.

Lincoln, Y. S., \& Guba, E. G. (2003). The Failure of Positivist Science. In Y. Lincoln and N. Denzin (Eds.), Turning Points in Qualitative Research. Tying knots in a Handkerchief (pp. 219-239). Walnut Creek, CA: AltaMira Press.

Lindsey, R. B., Roberts, L. M., \& CampbellJones, F. (2005). The Culturally Proficient School. An Implementation Guide for School Leaders. Thousand Oaks, CA: Corwin Press.

Marshall, C., \& Rossman, G. (1995). Designing Qualitative Research (2 ${ }^{\text {nd }}$ ed.). Thousand Oaks, CA: Sage. 
McCauley, L., \& Roddick, R. (2001). An Evaluation of Schools Support. Wellington: Ministry of Education.

Ministry of Education. (1993a). The National Education Guidelines. The Education Gazette, 72 (7), 1993.

Ministry of Education. (1993b). The New Zealand Curriculum Framework. Wellington: Ministry of Education.

Ministry of Education. (1999). Briefing for the Incoming Minister of Education. Wellington: Ministry of Education.

Ministry of Education. (2004). Statement of Intent - 2003-2008. Retrieved September 9, 2005, from http://www.minedu.govt.nz

Northouse, P. G. (2004). Leadership Theory and Practice. Thousand Oaks, CA: Sage.

Patton, M. Q. (1990). Qualitative evaluation and research methods. (2 ${ }^{\text {nd }}$ ed.). Newbury Park: Sage.

Prestine, N. A., \& Nelson, B. S. (2005). How can Educational Leaders Support and Promote Teaching and Learning? New Conceptions of Learning and Leading in Schools. In W. A. Firestone, \& C. Riehl (Eds.), A New Agenda for Research in Educational Leadership (pp. 4661). New York: Teachers College Press.

Sayles, L. R. (1964). Managerial Behaviour: Administration in Complex Organisations. New York: McGraw-Hill.

Sergiovanni, T. (2006). The Principalship. A Reflective Practice Perspective. USA: Pearson Education, Inc.

Shields, C., \& Sayani, A. (2005). Leading in the Midst of Diversity. The Challenge of Our Times. In F. W. English (Ed.), The Sage Handbook of Educational Leadership. Advances in Theory, Research, and practice (pp. 380-402). Thousand Oaks: Sage.

Stake, R. (2003). Case Studies. In N. Denzin \& Y. Lincoln, (Eds.), Strategies of Qualitative Inquiry (pp. 134-165). Thousand Oaks, CA: Sage.

Stoll, L., Bolman, R., McMahon, A., Wallace, M., \& Thomas, S. (2006). Professional Learning Communities: A Review Of The Literature. Journal of Educational Change, 7, 221258.

Strauss, A. (1987). Qualitative Analysis for Social Scientists. New York: Cambridge University Press.

Strauss, A., \& Corbin, J. (1990). Basics of qualitative research: Grounded theory procedures and techniques. Newbury Park, CA: Sage.

Strauss, A., \& Corbin, J. (1994). Grounded Theory Methodology. In N. K. Denzin, \& Y. S. Lincoln (Eds.), Handbook of Qualitative Research (pp. 273-285). Thousand Oaks, CA: Sage.

Strauss, A., \& Corbin, J. (1998). Basics of qualitative research: Techniques and procedures for developing grounded theory $\left(2^{\text {nd }}\right.$ ed.). Thousand Oaks, CA: Sage. 
Symes, I., Jeffries, L., Timperley, H. S., \& Lai, M. K. (2001). Schools' learning journeys: Evaluating a new approach to professional development in literacy at Viscount School. Set 2, 3-6.

Timperley, H., Smith, L., Parr, J., Partway, S., Mirams, S., Clark, S., Allen, M., \& Page, J. (2004). AUSAD Analysis and Use of Student Achievement Data: Final Evaluation Report. Report to the Ministry of Education. Auckland: Auckland Uniservices Ltd.

West, M., Jackson, D., Harris, A., \& Hopkins, D. (2000) Learning through leadership, leadership through learning: Leadership for sustained school improvement. In K. A. Riley, \& K. S. Louis (Eds.), Leadership for change and school reform: International perspectives (pp 30-49). London: Routledge Falmer.

Yin, R. K. (1994). Case Study Research: Design and Methods. Beverley Hills: Sage.

Yin, R. K. (2003). Case Study Research: Design and Methods ( $3^{\text {rd }}$ ed.). Thousand Oaks, CA: Sage. 